\title{
ANALYSIS OF ILLICIT DRUGS AND NICOTINE IN A BUCCAL TOBACCO BRAND MARKETED IN YEMEN
}

\author{
ANES AM THABIT*, AHMED MS AL-GHANI \\ Department of Pharmacy, Medical Sciences College, Al-Razi University, Yemen. Email: aneesalabsi1973@gmail.com
}

Received: 11 October 2019, Revised and Accepted: 13 December 2019

\begin{abstract}
Objectives: The objective of the present study was to check the potential presence of illicit drugs and to quantify the amount of nicotine in a buccal tobacco brand that had been observed to be increasingly used by Yemeni youths, since 2014, causing narcosis resembling states among them.

Methods: Thin-layer chromatography (TLC) described by the United Nations Office on Drugs and Crime (UNODC) was used to screen illicit drugs in the tested brand. The illicit drugs investigated included opiates, heroin, amphetamines, and cocaine. The TLC results were confirmed as recommended by the UNODC using color chemical tests. Identification and quantification of nicotine in the brand was carried out using an appropriate high-performance liquid chromatography (HPLC) system.
\end{abstract}

Results: No illicit drug was found in the tested tobacco brand. On the other hand, it was found that the amount of nicotine in just a single dose (sachet) of the buccal brand was $17.67 \pm 0.901 \mathrm{mg}$, which was 3.53 -fold greater than usual buccal dose of nicotine ( $5 \mathrm{mg}$ ).

Conclusion: With the exception of cannabis, opioids, and hallucinogens that were not investigated in this study due to technical obstacles, other major illicit narcotic drugs are not found in the brand. The brand contains high amount of nicotine/sachet. However, knowing that the user may use more than one sachet of the brands a day, there is a great potential of nicotine overdosing due to intake of the brand. This may cause a narcosis resembling state called "Nesbitt's paradox," characterized by reducing neuronal activity of the user.

Keywords: Buccal, Tobacco, Yemen, Nicotine, Thin-layer chromatography, United Nations Office on Drugs and Crime, Illicit drugs.

(C) 2020 The Authors. Published by Innovare Academic Sciences Pvt Ltd. This is an open access article under the CC BY license (http://creativecommons. org/licenses/by/4. 0/) DOI: http://dx.doi.org/10.22159/ajpcr.2020.v13i2.36034

\section{INTRODUCTION}

Tobacco is a product prepared from the leaves of the tobacco plant by curing them. The plant is a part of the genus Nicotiana and of the Solanaceae (nightshade) family. The pharmacological effects of tobacco such as euphoria and increase of blood pressure, heart rate, and blood sugar are due to "Nicotine" which is the main phytochemical in tobacco [1]. Nicotine is an alkaloid that acts as agonist to nicotinic acetylcholine receptors [2]. The usual daily consumption of nicotine as smoke is $384 \mathrm{mg}$ [3]. However, for therapeutic purposes mainly smoking cessation, lower amount is used daily. For instance, nicotine is used as transdermal patches at a dose of $45 \mathrm{mg} /$ day [4] and as buccal mucoadhesive tablet at a dose of $5 \mathrm{mg} /$ day [5]. Overdose of nicotine is associated with "Nesbitt's paradox," a case characterized by reducing neuronal activity of the user [6].

Illegal tobacco brands may contain illegal materials including illicit drugs. According to the United Nations Office of Drugs and Crime (UNODC), the major illicit drugs are opium (the coagulated juice of the opium poppy), opiates (natural such as morphine and codeine and semi-synthetics such as heroin), opioids (synthetic analogs of opiates, e.g. methadone), cannabis, coca (crude leaf of the genus Erythroxylon) and cocaine (major psychoactive alkaloid of coca), and amphetamines (amphetamine-type stimulants and central nervous system depressants such as benzodiazepines, e.g. diazepam), and methaqualone and hallucinogens such as (+)-lysergide and phencyclidine [7].

\section{METHODS}

\section{Instruments}

High-performance liquid chromatography (HPLC) system (Shimadzu ${ }^{\circledR}$ LCsolution Analysis, Japan) and ultraviolet (UV) spectrophotometer (Shimadzu, UV-1800, Japan) were used. The stationary phase of thin- layer chromatography (TLC) system was plates of silica gel GF254 (Merck, Germany).

Materials

Reference standards of standard nicotine 98\% were purchased from the global market (Riedel-de Haen, Germany). Standards of lidocaine, codeine, ephedrine, and caffeine were gifts from the Yemen Egyptian Pharma Co. Others materials were all at least analytical grade.

\section{Experiments}

\section{TLC screening of illicit drugs}

Five TLC tests were carried out for at least a duplicate run/test. The tests were carried out according to recommendation of the UNODC where each category of illicit drugs was investigated using two or three different mobile phases [8-11] as follows:

Test 1 (used to detect opiates, amphetamines, cocaine, methaqualone, and diazepam): The mobile phase was composed of methanol: conc. ammonia (100:1.5) and the reference standards used were nicotine, codeine, ephedrine, lidocaine, and caffeine.

Test 2 (used to detect opiates and amphetamines): The mobile phase was ethyl acetate: methanol:conc. ammonia (85:10:5) and the standard references used were nicotine, codeine, and ephedrine.

Test 3 (used to detect amphetamines, cocaine, methaqualone, and diazepam): The mobile phase was cyclohexane: toluene:diethylamine (75:15:10) and the reference standards used were nicotine, ephedrine, lidocaine, and caffeine.

Test 4 (used to detect opiates): The mobile phase was toluene: acetone:ethanol: conc. ammonia $(45: 45: 7: 3)$ and the reference standards used were nicotine and codeine.

Test 5 (used to detect cocaine): The mobile phase was chloroform: dioxane:ethyl acetate: ammonia (29\%) (25:60:10:5) and the reference standards used were nicotine and lidocaine. 
In all TLC tests, the tank used $(50 \times 20 \mathrm{~cm})$ with glass and lined with adsorbent paper. TLC plates had thickness of $0.25 \mathrm{~mm}$ and dimensions of $20 \times 10 \mathrm{~cm}$. A spotting line was made on the plate at $1 \mathrm{~cm}$ from the bottom of the plate. At least five spots were applied in the TLC including one spot of $5 \mu \mathrm{l}$ (of the standard solution), two spots $(1 \mu \mathrm{l}$ and $2 \mu \mathrm{l}$ of the sample solution), and $2 \mu \mathrm{l}$ of the negative control solution. The size of spot had a range from 1 to $2 \mathrm{~mm}$ (i.e., $\leq 2 \mathrm{~mm}$ ). The spacing between spots was at least $1 \mathrm{~cm}$. After each application, each spot was dried on cold air. The elution of mobile phase was permitted to reach the developing line (developing end). This line was at $10 \mathrm{~cm}$ above the spotting line (i.e., $11 \mathrm{~cm}$ from the bottom) in a $20 \mathrm{~cm}$ length plate. Once the mobile phase reached the developing end, the plate was immediately from the tank. Before visualization, the TLC plate was dried at room temperature using a cold air blower. The absence of any trace of odor in the plate indicated well drying. Visualization was made under UV light at $254 \mathrm{~nm}$. Each spot appeared on the plate by visualization represented an independent compound. Retention factor $\left(R_{f}\right)$ of every spot was calculated as follows:

$$
R_{f}=100 \times d s / d m
$$

Where, $d s$ was the distance of the spot from the starting line and $d m$ was the elution distance of mobile phase.

\section{Calibration and correction factors}

To calibrate retention factor $\left(R_{f}\right)$ obtained from the analysis of tobacco sample using the mobile phases in tests 1,2 , or 3 , a standard calibration curve for each test was constructed between experimental standard $R_{f}$ ( $x$ axis) and UNODC $R_{f}(y$ axis). A standard solution $(5 \mathrm{mg} / \mathrm{ml}$ ) for each test was prepared by dissolving the reference standard in methanol.

For tests 4 and 5, only one standard was used in each test. As a result, calibration curve could not be constructed, and hence, a correction factor $(C . F)$ was determined for each test as follows:

$$
\text { C.F }=R_{f 1} R_{f 2}
$$

Where, $R_{f 1}$ was the retention factor of the standard reported by UNODC and $R_{f 2}$ was the retention factor of the standard obtained experimentally.

\section{Sample analysis}

The sample test solution: $5 \mathrm{mg} / \mathrm{ml}$ sample solution was prepared by grinding $(50 \mathrm{mg}$ ) of tobacco and dissolving up $10 \mathrm{ml}$ with methanol.
Alongside with standard and sample solutions, a negative control solution composed of the mobile phase itself was used as control.

For tests 1,2 , and 3 , the corrected $R_{f}$ of each spot observed in the tobacco sample was determined from the linearity equation $(y=a x+b)$ of the standard calibration curve as follows:

Corrected $R_{f}$ sample spot $=\left(\right.$ slope $*$ experimental $\left.R_{f}\right)+$ intercept

Whereas, for tests 4 and 5 , the sample corrected $R_{f}$ of each spot was calculated as follows:

$$
\text { Corrected } R_{f} \text { of spot sample }=R_{f s} \times C . F
$$

Where, $R_{f s}$ was the retention factor of the spot obtained from analysis of tobacco sample experimentally and C.F. was the correction factor.

\section{Chemical color tests}

To confirm results obtained from TLC, the suspect spot was isolated from the TLC plate and subjected to the chemical test reported by the UNODC [8-11] as follows:

- Marquis test: Formaldehyde, glacial acetic acid, and conc. sulfuric acid to test opiates and amphetamines.

- Scott's test: Cobalt thiocyanate, glycerin, conc. $\mathrm{HCl}$, and chloroform to test cocaine

- Fischer-Morris test: Formic acid and sodium nitrite solution to test methaqualone and diazepam.

\section{HPLC analysis of nicotine}

The qualitative and quantitative analysis of nicotine in tobacco sample was carried out using HPLC system reported in the literature [12] with slight modification. The modification was only changing the column length from $250 \mathrm{~mm}$ to $150 \mathrm{~mm}$. The system was equipped with C18 column $(150 \times 4.6 \mathrm{~mm}, 5 \mu \mathrm{m})$ as a stationary phase. The mobile phase was a mixture of methanol/water/0.1 M acetate buffer solution (pH 4.0)/acetonitrile (13:65:20:2) which was adjusted to $\mathrm{pH} 6.3$ with triethylamine. The system operated at a flow rate of $1 \mathrm{~mL} / \mathrm{min}$ and the detection was carried out at UV wavelength: $262 \mathrm{~nm}$.

A standard calibration curve for HPLC analysis was constructed using nicotine standard solutions in methanol with concentrations at a range of $1.25-20 \mu \mathrm{g} / \mathrm{ml}$.

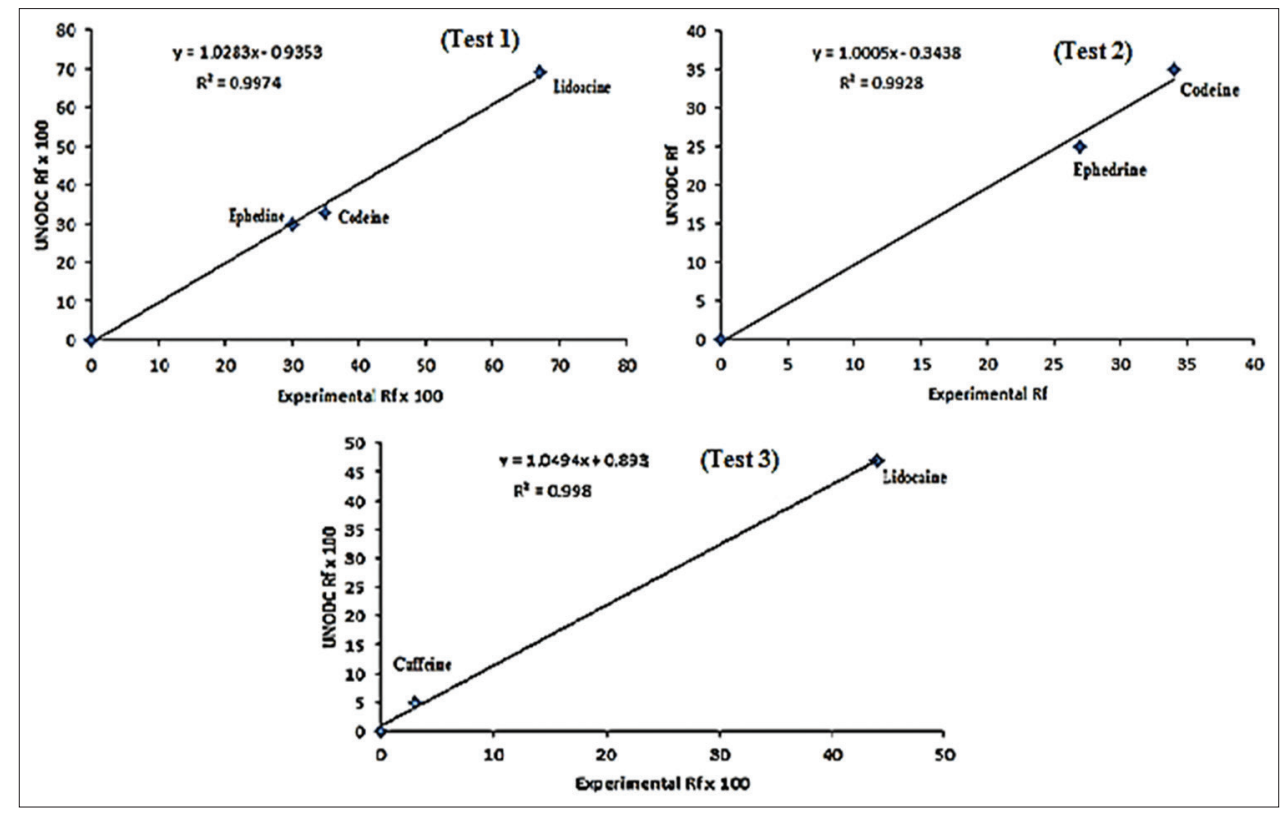

Fig. 1: Standard calibration curves of TLC (tests 1, 2, and 3) 


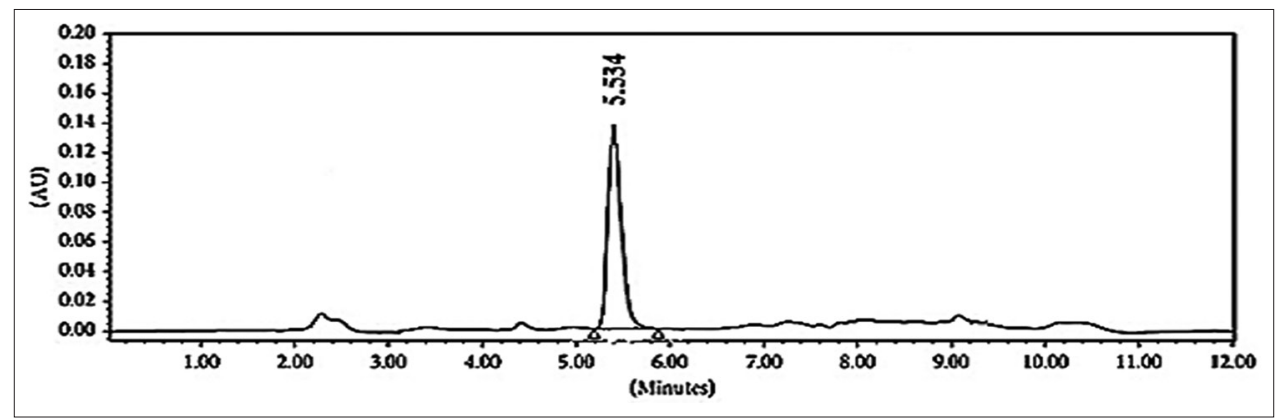

Fig. 2: HPLC chromatogram of nicotine standard $(10 \mu \mathrm{g} / \mathrm{ml})$

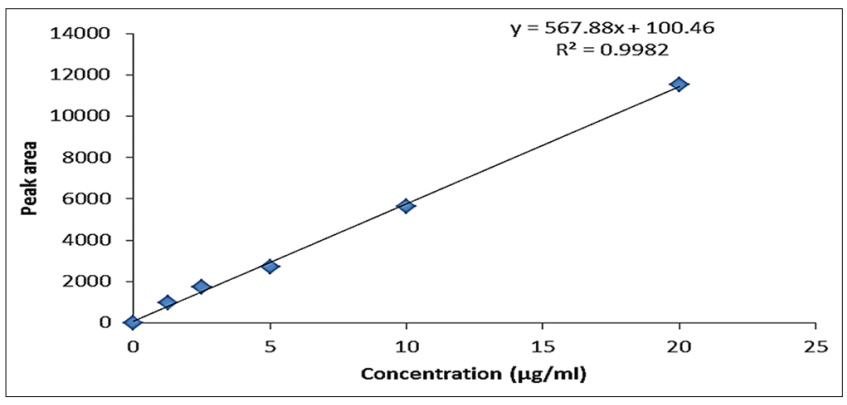

Fig. 3: Standard calibration curves of HPLC analysis of nicotine $(1.25-20 \mu \mathrm{g} / \mathrm{ml})$

For analysis of tobacco sample, the content of one sachet $11 \mathrm{~g}$ of tobacco; theoretically containing $5 \mathrm{mg}$ nicotine as reported in the literature for buccal mucoadhesive tablet) was ground and then dissolved and properly diluted in methanol to yield a theoretical concentration (Ct) of $1.92 \mu \mathrm{g} / \mathrm{ml}$. The peak area of the sample solution was measured at $262 \mathrm{~nm}$. The peak area of the sample was then introduced into the standard curve equation to determine practical nicotine concentration and then the amount of nicotine (mg) in the sample.

\section{RESULTS AND DISCUSSION}

\section{TLC screening of illicit drugs}

The calibration curves for correlation of experimental standard $R_{f}$ obtained in this study with those reported by the UNODC using different mobile phases in TLC tests 1,2 , and 3 showed straight lines with linearity coefficients of $0.9974,0.9928$, and 0.998 , respectively, as shown in Fig. 1. The linearity equations obtained from each test were used to calculate corrected $R_{f}$ for spots appeared in analysis of samples of the buccal tobacco brands (Fig. 1 and Table 1). On the other hand, corrected $R_{f}$ of tobacco samples in TLC tests 4 and 5 was calculated using correction factors (Tables 1 and 2).

Comparison of corrected $R_{f}$ of spots appeared in tobacco samples to those reported by the UNODC [8-11], as demonstrated in Table 2, provided many suspected illicit drugs in each TLC test with the greatest number of suspects observed in TLC test 1 where the mobile phase was a mixture of ethyl acetate: methanol:conc. ammonia (85:10:5). Nicotine was a common suspect in all tests.

To confirm the identity of experimental sample spots, each spot was isolated from the TLC plate and then subjected to a number of color chemical according to the classes of the suspects. However, the relevant chemical tests (Table 3) revealed negative results for the presence of opiates, amphetamines, cocaine, diazepam, and methaqualone.

HPLC analysis of nicotine

Using the HPLC system described earlier, the retention time of nicotine standard was $5.5 \pm 0.02$ min (Fig. 2), which was a quite different
Table 1: Correction factors for TLC tests 4 and 5

\begin{tabular}{lllll}
\hline \multirow{2}{*}{$\begin{array}{l}\text { TLC } \\
\text { test no. }\end{array}$} & Standard & $\boldsymbol{R}_{\boldsymbol{f}}$ standard & $\begin{array}{l}\text { Correction } \\
\text { factor (C.F) }\end{array}$ \\
\cline { 3 - 4 } & & Experimental & UNODC & \\
\hline 4 & Codeine & 38 & 40 & 1.052 \\
5 & Lidocaine & 76 & 77 & 1.01 \\
\hline
\end{tabular}

Table 2: Suspected drugs in TLC analysis of buccal tobacco sample

\begin{tabular}{|c|c|c|}
\hline $\begin{array}{l}\text { TLC test } \\
\text { no. }\end{array}$ & Corrected $\boldsymbol{R}_{f}$ & Suspected drug \\
\hline 1 & 66.1 & $\begin{array}{l}\text { Cathinone }\left(R_{f}=66\right) \text {, cocaine }\left(R_{f}=67\right) \text {, } \\
\text { noscapine }\left(R_{f}=64\right) \text {, lidocaine }\left(R_{f}=69\right) \text {, } \\
\text { nicotine }\left(R_{f}=63\right)\end{array}$ \\
\hline 2 & 92.5 & Nicotine $(R=85)$ \\
\hline 3 & 25 & Nicotine $\left(R_{f}=32\right)$, tetracaine $\left(R_{f}=25\right)$ \\
\hline 4 & 74.7 & Papaverine $\left(R_{f}=72\right)$, nicotine $\left(R_{f}=48\right)$ \\
\hline 5 & 48.5 & $\begin{array}{l}\text { Lidocaine }\left(R_{f}=47\right) \text {, } \\
\text { cinnamoylcocaine }\left(R_{f}=51\right) \text {, nicotine }\left(R_{f}=48\right)\end{array}$ \\
\hline
\end{tabular}

Table 3: Results of color chemical tests for spots isolated from TLC plates

\begin{tabular}{lll}
\hline Test & Result & Interpretation \\
\hline Marquis & $\begin{array}{l}(-\mathrm{ve}) \\
(-\mathrm{ve})\end{array}$ & $\begin{array}{l}\text { No opium alkaloid or heroin is present } \\
\text { No amphamines are present }\end{array}$ \\
Scott's & $(-\mathrm{ve})$ & $\begin{array}{l}\text { No cocaine, tetracaine, or lidocaine is } \\
\text { present }\end{array}$ \\
Fischer-Morris & $(-\mathrm{ve})$ & No methaqualone or diazepam is present \\
\hline
\end{tabular}

Table 4: Nicotine content per $1 \mathrm{~g}$ (one sachet) of buccal tobacco brand

\begin{tabular}{ll}
\hline Run & Nicotine $(\mathbf{m g}) / \mathbf{1}$ g tobacco \\
\hline 1 & 17.42 \\
2 & 16.92 \\
3 & 18.67 \\
Average \pm SD & $17.67 \pm 0.901$ \\
Ratio to buccal dose of nicotine (5 mg) & $3.53: 1$ \\
\hline
\end{tabular}

from that reported in the literature [12] as a result of the system modification applied in this study. However, the system was efficient to distinguish between a wide range of nicotine concentration (1.25$20 \mu \mathrm{g} / \mathrm{ml}$ ) as observed in the standard calibration curve (Fig. 3) with linearity of coefficient of 0.9982 . The curve equation was, therefore, used to calculate the amount of nicotine in the buccal tobacco, as shown in Table 4. The relevant table showed that for one sachet (one dose containing $1 \mathrm{~g}$ of buccal tobacco), the amount of nicotine was $17.67 \pm 0.901 \mathrm{mg}$, which was 3.53 -fold greater than the daily dose of 
nicotine (5 $\mathrm{mg}$ ) as buccal nicotine [8]. This finding was an overdose of nicotine, especially if the user takes more than one sachet of the buccal tobacco a day.

\section{CONCLUSION}

There are no opiates, amphetamines, cocaine, diazepam, or methaqualone found in the investigated buccal tobacco brand. However, the amount of nicotine in the brand is considered as an overdose which may cause "Nesbitt's paradox" or similar cases of lower neuronal activity in the user. It should note that other types of illicit drugs including cannabis, opioids, and hallucinogens are still required to be investigated in the brand.

\section{AUTHORS' CONTRIBUTIONS}

The correspondent author conceived the idea, developed the theory, and performed the calculations of the presented work. All authors participated in conducting experiments, discussing the results, and contributing to the last manuscript.

\section{CONFLICTS OF INTEREST}

The authors declare that there are no conflicts of interest regarding the publication of this article.

\section{REFERENCES}

1. Richard R. Tobacco. The Encyclopedia of Psychoactive Substances. Available from: https://www.biopsychiatry.com/tobacco. [Last accessed on 2018 Nov 21]
2. Nicotine Compound Summary. Available from: https://www.pubchem. ncbi.nlm.nih.gov/compound/nicotine. [Last accessed on 2018 Dec 15].

3. Lawler TS, Stanfill SB, deCastro BR, Lisko JG, Duncan BW, Richter P, et al. Surveillance of nicotine and $\mathrm{pH}$ in cigarette and cigar filler. Tob Regul Sci 2017;3:101-16.

4. Ebbert JO, Post JA, Moyer TP, Dale LC, Schroeder DR, Hurt RD. Nicotine percentage replacement among smokeless tobacco users with nicotine patch. Drug Alcohol Depend 2007;89:223-6.

5. Lewis S, Subramanian G, Pandey S, Udupa N. Design, evaluation and pharmacokinetic study of mucoadhesive buccal tablets of nicotine for smoking cessation. Indian J Pharm Sci 2006;68:829-31.

6. Parrott AC. Nesbitt's paradox resolved? Stress and arousal modulation during cigarette smoking. Addiction 1998;93:27-39.

7. United Nations Office on Drug and Crimes. Terminology and Information on Drugs. $3^{\text {rd }}$ ed. New York: United Nations Publications; 2016.

8. Laboratory and Scientific Section, United Nations International Drug Control Program Vienne. Recommended Methods for Testing Opium, Morphine and Heroin. New York: United Nations; 1998.

9. Laboratory and Scientific Section, United Nations Office on Drug and Crimes. Recommended Methods for the Identification and Analysis of Amphetamine, Methamphetamine and their Ring-substituted Analogues in Seized Materials. New York: United Nations; 2006.

10. Laboratory and Scientific Section, United Nations Office on Drug and Crimes. Recommended Methods for the Identification and Analysis of Cocaine in Seized Materials. New York: United Nations; 2012.

11. Laboratory and Scientific Section. United Nations Office on Drug and Crimes. Recommended Methods for the Identification and Analysis of Methaqualone Mecloqualone in Seized Materials. New York: United Nations; 2010.

12. Fukumoto M. A handbook of practical analysis. In: Suzuki O, Watanabe K, editors. Drugs and Poisons in Humans: Nicotine and Cotinine. Germany: Springer; 2005. p. 499-508 